\title{
Difference in outcome of shoulder surgery between workers' compensation and nonworkers' compensation populations
}

Paul Koljonen · Calvin Chong • Daniel Yip

Published online: 25 September 2008

(C) Springer-Verlag 2008

Erratum to: International Orthopaedics (SICOT)

DOI 10.1007/s00264-007-0493-8

In the conclusion paragraph, the correct text should be:

"All but one of the 28 articles selected for this review demonstrated a POSITIVE correlation between WC status and poor outcome." instead of NEGATIVE

The online version of the original article can be found at http://dx.doi. org/10.1007/s00264-007-0493-8.

P. Koljonen $(\bowtie) \cdot$ C. Chong $\cdot$ D. Yip

E7 Manhattan Court, 1 Alnwick Road, KLN,

Hong Kong, China

e-mail:paulak@gmail.com 